\title{
AVATAR, GAME E SUBJETIVIDADE: DIÁLOGOS CONTEMPORÂNEOS
}

\author{
Danielly Amatte Lopes
}

\begin{abstract}
Resumo: O processo de formação de identidade por parte do indivíduo vem sendo objeto de investigação de diversos campos teóricos ao longo do tempo. Estabelecer os limites entre o que entendemos como "eu" e, por conseguinte, o "não-eu" faz partes das inquietações investigadas pelo campo das ciências sociais nesse processo de sucessivas modificações pelas quais as relações sociais foram passando a medida que a história corria. Verifica-se que a relação estabelecida entre o homem e as novas tecnologias, especialmente aquelas que permitem um desdobramento para além do mundo físico, introduziram um novo aspecto a ser analizado nesse processo formativo. O homem contemporâneo tem como possibilidade cotidiana habitar um universo digital e o estabelecimento de novos limites para a sua subjetividade é uma questão facilmente verificável nos jogos digitais. O presente artigo busca estabelecer uma discussão sobre a identidade contemporânea e sua relação com os jogos digitais, sobretudo com a figura do avatar, elemento que personifica sua existência nesses artefatos. Para isso usamos as contribuições de autores como Guattari, Hall, Sibila entre outros, investigando o avatar como um possível fragmento/desdobramento da identidade do jogador contemporâneo.
\end{abstract}

Palavras-chave: avatar, games, comunicação, identidade, contemporâneo

\section{GAME ${ }^{1}$ E IDENTIDADE CONTEMPO-RÂNEA: CONCEITOS E PROCESSOS DE FORMAÇÃO}

O processo de formação de identidade por parte de cada indivíduo vem sendo objeto de investigação das mais diversas áreas e campos teóricos. Sociologia, antropologia, comunicação, psicanálise e tantos outros a muito buscam identificar quais as questões negociadas ao determinarmos quem somos, tanto individual, quanto coletivamente. Se antes mesmo da possibilidade de uma interferência tecnológica esse assunto já não era um dos mais fáceis de se delimitar, a influência de uma tecnocultura cada vez mais dinâmica e imersiva acrescenta nesse momento ainda mais pontas soltas em torno da pergunta "quem sou eu?".

Essa questão conta hoje com mais uma possibilidade de ampliação, aquela que abrange o eu jogador. A partir do momento em que alguns jogos digitais permitem ao jogador customizar um agente (avatar) que o representa nesse novo ambiente, amplia-se também aquilo que podemos entender como identidade contemporânea. Sabe-se que o humano sempre foi mutante, um ser adaptativo que construía redes, sociais e de poder, que nos ajudavam a definir melhor a identidade dele. Uma identidade múltipla e polifônica capaz de congregar as subjetividades de cada indivíduo, o imaginário compartilhado em diversos grupos que o acolhem, sendo constantemente influenciada pelas modificações que

1 Na construção desse texto consideramos "games" e "jogos digitais" como sinônimos, nos referindo a todo e qualquer elemento que use a imagem de síntese, a construção de narrativa e os elementos de ludicidade em sua essência compositiva. 
ocorrem nestas instâncias.

Buscar uma cartografia da formação da identidade contemporânea implica em, por exemplo, entender como a subjetividade se relaciona com esse processo em que o avatar se torna um mediador entre o jogador, a interface do jogo e o uso de um complexo sistema que regula o metaverso ${ }^{2}$ por onde ele se aventura. Entender a relação entre jogador e avatar ganha importância pois, ao compreender melhor a experiência do jogador e sua relação com o avatar, podemos também desenvolver uma compreensão a respeito do impacto cultural do avatar e, consequentemente, sua relação com os processos de formação de identidade na contemporaneidade.

\subsection{Identidade contemporânea e a produção de subjetividades}

A identidade e a cultura de um determinado grupo surgem a partir de diversas influências. A música, a ciência, a prosa, a tecnologia são exemplos concretos dessas expressões culturais que se alimentam de fontes ideológicas e sociais distintas, influenciando a formação do que cada indivíduo entende por si mesmo. Resgatando o pensamento de Foucault ${ }^{3}$ ao falar do desaparecimento do sujeito, há sempre uma cultura que nos precede. Um complexo formador de estruturas que ajudam a definir a sociedade. Para Lemos (2009):

A riqueza de qualquer sociedade sempre está ligada à complexidade de sua cultura, isto é, à força do seu poder criativo e empreendedor. A comunicação, neste sentido, é a forma pela qual uma sociedade põe em marcha e intercambia o conjunto de seus empreendimentos, sejam eles artísticos, sociais, políticos, científicos ou técnicos. Uma cultura complexa é uma cultura plural, aberta, circulando livremente pelo corpo social. A criatividade está na originalidade da circulação de diversas formas culturais, incluindo aí sua riqueza artística e intelectual, seu habitus social, sua criatividade simbólica, imaginária, científica e técnica. (LEMOS, 2009, p.13)

A identidade de um indivíduo se formaria justamente nessa circulação das formas culturais, o levando a assumir diversos posicionamentos. Para Vera França (2002), "a identidade tem a ver com discursos, objetos, práticas simbólicas que nos posicionam no mundo". Se associarmos isso à visão de Castells (2003), que entende identidade como "o processo de construção de significado com base em um atributo cultural, ou ainda um conjunto de atributos culturais inter-relacionados, o(s) qual(ais) prevalece $(\mathrm{m})$ sobre outras fontes de significado", podemos identificar como terreno para a construção de identidade, os campos do discurso e das representações (FRANÇA 2002).

Essas representações na sociedade contemporânea estão cada vez mais ligadas às imagens visuais (como as encontradas nos games, incluindo aí o avatar) e mentais. Somos, sobretudo, frutos de uma situação paradoxal, onde a sociedade ocidental pósmoderna propiciou o desenvolvimento das imagens visuais e verbais, mas ao mesmo tempo possui uma desconfiança dessas imagens que ajudou a desenvolver. A lógica e a razão tentam prevalecer sobre o mítico e o intuitivo ainda tendo como base o pensamento aristotélico ${ }^{4}$. Um pensamento dual, onde as coisas que são se opõem às coisas que nãosão.

Diante desse pensamento dual também somos apresentados a uma oposição entre

\footnotetext{
2 O uso da expressão "metaverso" é atribuído a Neal Stephenson no início dos anos 1990 em seu romance Snow Crash, mas em termos de descrição já poderiam ser visto no clássico livro Neuromancer, de William Gibson. Segundo Stephenson temos uma ampliação do espaço do mundo físico dentro de um espaço digital (ou virtual para usarmos palavras do autor), onde os humanos realizam experiências de interação entre si e com o jogo, amparados por um suporte lógico digital radicado no ciberespaço.

3 Segundo Diniz (2013): "o pensamento de Foucault, no que se refere ao desaparecimento do Sujeito no sentido cartesiano do termo, ou seja, o Eu penso, logo existo, é substituído por Algo pensa por mim, ou Algo pensa através de mim."

4 Mais adiante resgataremos novamente o pensamento Aristotélico para abordar o conceito de harmonia e a relação entre o todo e as partes, discutindo assim a fragmentação da identidade do sujeito contemporâneo.
} 
o sujeito individual e o coletivo que, segundo Guattari (1992) precisa ser superada em direção à conceituação das subjetividades. Para o autor, é preciso considerar a subjetividade para além dos sistemas tradicionais de determinação, opondo super e infraestruturas. Segundo Guattari, os diferentes registros que concorrem para o engendramento da subjetividade não se constroem por meio de hierarquias obrigatórias ou definitivas. A subjetividade seria, de fato, plural e polifônica 5 e, não necessariamente, parte de um processo emancipador do sujeito. Ainda segundo o autor, os fatores subjetivos vêm ganhando um papel preponderante na história contemporânea, sobretudo a partir do momento em que foram assumidos pelo mass mídia e ganharam alcance global.

\begin{abstract}
De um modo geral, pode-se dizer que a história contemporânea está cada vez mais dominada pelo aumento das reivindicações de singularidade subjetiva - querelas linguísticas, reivindicações autonomistas, questões nacionalísticas, nacionais que, em uma ambiguidade total, exprimem por um lado uma reivindicação do tipo liberação nacional, mas que, por outro lado, se encarnam no que eu denominaria reterritorializações conservadoras de subjetividade. (GUATARRI, 1992, p.13)
\end{abstract}

Guattari postula que a subjetividade apareça do fluxo constante entre individual e coletivo, sendo fabricada não só no âmago do sujeito, mas também fabricada nas grandes máquinas sociais, na cultura de massa. Devemos admitir que cada indivíduo, cada grupo faz uso de um sistema próprio de modelagem dessa subjetividade, se apropriando não só das "demarcações cognitivas" (Guattari, 1992), mas também da maneira como, indivíduo e grupo, se posiciona em relação aos seu afetos, angústias, pulsões e inibições. De acordo com Diniz:

[...] a conceituação de subjetividades de Guattari aponta para novos vieses reflexivos que acreditamos, permitem aprofundar a reflexão sobre o estatuto do humano na contemporaneidade. Lembrando que as subjetividades de Guattari não são produtos do pensamento determinista, nem do humanismo moderno. (DINIZ, 2013, p.03)

Seguindo o pensamento de Guattari (1992) a definição da subjetividade se dá quando o indivíduo ou o grupo emergem como territórios autorreferentes, contíguos a uma alteridade subjetiva. Desloca-se o foco unicamente da questão do sujeito e observa-se o coletivo, uma multiplicidade que está além do indivíduo. É um processo de tomada da relação sujeito/objeto como princípio, evocando condições de produção intersubjetivas e instâncias sugestivas ou identificatórias (como a etologia, a interação, a hibridação humano-máquina etc.). Para a formação da identidade individual há de se examinar o fluxo entre o indivíduo e o coletivo, assim como observar as influências que a relação desenvolvida entre o indivíduo e os objetos que o circundam.

O ambiente dos jogos digitais se configura como um lugar que nos permite fazer essa análise, já que a interação entre o jogador e o jogo e entre múltiplos jogadores, como nos casos dos MMORPG ${ }^{6}$, são parte desse fluxo que Guattari nos incentiva a observar. O avatar aparece ora como objeto, ora como o próprio sujeito em interação com o jogo, inserido em um território autorreferente, em um fluxo entre o indivíduo e o coletivo que o circundam.

Estamos diante de dispositivos de produção de identidade que em certos contextos se individua e, em outras condições, apresenta uma subjetividade que se faz coletiva. Um processo que se liga também ao enorme desenvolvimento produções de subjetividade ligadas diretamente as tecnologias e as máquinas, como no caso da relação entre o

\footnotetext{
5 Guattari se apropria da interpretação Bakhtiniana do termo "polifonia"

6 Os Massively Multiplayer Online Game (MMORPG) são uma vertente de jogos cuja dinâmica pressupõe a "presença" do jogador em um mundo com regras e dinâmicas próprias, sendo o avatar o agente dessa presença no jogo. Planejado para suporta milhares de jogadores ao mesmo tempo os MMORPG possibilitam ao jogador interagir em tempo real com outros jogadores presentes no ambiente, simulando algo muito parecido com nossas relações sociais. (Castronova, 2001)
} 
jogador, os jogos digitais e os avatares. As transformações tecnológicas, segundo Guattari (1992), acabam por nos obrigar a considerar duas tendências simultâneas e contraditórias. Se por um lado identifica-se uma tendência homogeneizante - geralmente reducionista e universalizante da subjetividade, produzida pelo que seria uma igualdade de condições promovidas pela aproximação do humano com a máquina encontrada nos jogos digitais - por outro lado temos um reforço à singularização de determinados componentes - como a produção de avatares com um grau de customização cada vez maior. O poder de escolha, a ilusão de domínio sobre o corpo, a máquina, o sujeito, cria uma diferenciação e uma heterogeneidade promovidas pelo uso dos recursos tecnológicos como dispositivos de produção de subjetividade.

Essas máquinas tecnológicas, entre elas os jogos digitais, não só operam no núcleo da subjetividade do homem contemporâneo influenciando aspectos cognitivos, mas também operam modificações da sensibilidade desse homem, seus afetos e seus fantasmas inconscientes. Abre-se espaço para uma mudança de paradigma onde novos seres emergem dessa zona que mescla natural e artificial, uma mistura que pode tanto ser física, quanto conceitual. De acordo com Nikolas Rose, (apud Silva 2001) essa mudança de paradigma levou também a uma proliferação "de novas imagens de subjetividade; como socialmente construídas; como dialógica; como inscrita na superfície do corpo; como espacializada, descentrada, múltipla, nômade". No contexto pós-moderno aparece a exigência de que sejamos multi em todos os aspectos: multifacetados, multidentitários, multiperceptivos. De acordo com Diniz (2013):

O conceito de subjetividade contraposto ao de sujeito, corrobora na compreensão das novas subjetividades produtos desse ser humano maquínico em estreita relação com dispositivos produtores de signos. (...) Em relação às subjetividades reterritorializadas, entendemos as construções das subjetividades no campo em que os vínculos entre ser humano e máquina são tensionados de forma a enfatizar relações que tendem a abolir as fronteiras do maquínico como elemento que diferenciaria o humano de uma construção tecnológica. (...) Não se trataria mais de definir o humano, sua essência ou substância, mas sim, de compreender como os processos operados pela linguagem constroem tanto a figura do humano maquínico como do maquínico humanizado, ou na ocorrência de nossa reflexão, do ciborgue como figura central. (DINIZ, 2013, P.04)

Diniz resgata em seu trabalho a discussão do conceito de ciborgue ${ }^{7}$ e como esse ser híbrido humano-máquina contribui para uma reflexão sobre o estatuto do humano.
De qualquer modo, o fato é que há uma reflexão sobre o estatuto do humano e sua transformação para o maquínico sendo construída e, para nós, o que torna tal reflexão relevante é que as tecnologias - tanto biológicas, quanto maquínicas, estão modificando nossa percepção e, desse modo, construindo novas formas sensórias e novas formas de ver o mundo. Como resultado desse processo, temos, entre outros desdobramentos, novas linguagens que articulam essa percepção à comunicação e às construções culturais. (DINIZ, 2013, p.07)

Surgem novas linguagens e são formadas subjetividades que permitem ao homem contemporâneo entender sua aproximação com os elementos tecnológicos como parte formadora da sua identidade. O viver biologicamente, em uma instância física, é acrescido de uma existência em forma de código fonte, sob a forma de dado e, no caso dos jogos digitais, sob a forma de imagem de síntese. Estamos diante de uma proposta de ampliação do self, contrapondo e superpondo fragmentos formadores do que o homem contemporâneo entende por ele-mesmo.

\footnotetext{
7 Há uma série de trabalhos que se aventuram na busca por uma definição para o termo "ciborgue". Uma das visões mais difundidas é a apresentada por Donna Haraway: "Um ciborque é um mecanismo cibernético, um híbrido de máquina e organismo, uma criatura da realidade social, bem como um personagem da ficção (...) O ciborgue é um organismo cibernético, uma fusão do orgânico e do técnico forjado em particular, por práticas históricas e culturais" (HARAWAY: 1991, p. 149).

8 "Quando nos referimos ao self pensando na dignidade única de um ser humano, pensando nos lugares e nas pessoas que moldaram nossas vidas e que afirmamos nos pertencer e viver em nós, estamos falando, evidentemente, do self autobiográfico. Este é o estado cerebral para o qual a história cultural da humanidade tem maior importância" (DAMASI0, 2000, p.294).
} 
O sujeito contemporâneo não é mais UNO nem mesmo no que diz respeito às linguagens e teorias com as quais convive. São linguagens híbridas, teorias que ora se sobrepõem e ora se superpõem. Nasce uma combinação de criaturas pós-humanas e outros híbridos tecnoculturais. A questão da identidade, como aponta Hall (apud SILVA 2000), não mais necessita da história e da cultura apenas para dizer quem somos, e, sim, para apontar o que podemos vir a ser e como podemos ser representados por nós mesmos e pelo outro.

No mundo dos jogos digitais o avatar se apresentam como corporeidade em um ambiente digital, permitindo ao jogador vivenciar esse novo espaço de ação. 0 ambiente dos jogos eletrônicos propicia momentos onde o elemento lúdico se encarrega de tornar mais difusa essa diferenciação, a identidade agora fluida encontra no jogo digital uma nova possibilidade de ocupação.

\section{IDENTIDADE E AMBIENTES VIRTUAIS: DESLOCAMENTOS PROVOCADOS PELA CIBERCUL- TURA}

Pensar nesse processo de construção de uma identidade dentro dos ambientes virtuais nos leva a examinar um desdobramento da figura do humano, promovida agora, diretamente pela hibridação com a tecnologia. Essa hibridação implica num reordenamento não só da identidade do indivíduo, mas também nos leva a revisitar algumas noções que já foram mais fixas para nós.

Essa formação discursiva diz respeito aos universos que habitamos contemporaneamente e os valores atribuídos a diferentes aspectos simbólicos, se ligando também a uma identidade subjetiva que não é fixa e nem tão pouco unificada. Trata-se de um momento em que o humano habita um mundo mutante que nos obriga constantemente a readaptar sentidos e dogmas. Há, portanto, uma instabilidade estrutural naquilo que nos ajudava a identificar o "sujeito sociológico" (HALL 2005), nos encaminhando para uma construção de um sujeito pós-moderno que precisa contemplar uma multiplicidade no que tange o Self.

\subsection{0 uno, o fragmentado e o conceito aristotélico de harmonia}

O sujeito pós-moderno não é mais UNO nem mesmo no que diz respeito às linguagens e teorias com as quais ele convive. Esse sujeito reorganiza sua própria identidade para um ordenamento de diferentes selfs, algo próximo do que Aristóteles, em sua obra sobre a Arte poética propôs. Nesse sentido, resgatando a ideia de HARMONIA proposta pelo pensador, encontramos a unidade da identidade do sujeito da contemporaneidade diretamente ligada à composição harmônica de suas diversas identidades.

Podemos, dessa maneira, resgatar o entendimento de beleza aristotélica. Beleza esta que decorre de certa harmonia (ordenação) existente entre as partes do objeto, no caso o sujeito da contemporaneidade, em relação ao todo. Nesse sentido, podemos afirmar que o belo aristotélico está na proporção e harmonia das partes com o todo, a unidade em si é provida pela harmoniosa ordenação das diferentes partes que compõem o objeto.

A filosofia aristotélica nos apresenta um embate entre o caos e a harmonia, transferindo para questão da Beleza o conceito de justa medida, que nesse caso, nasceria do equilíbrio entre as partes e o todo. Podemos transpor essa mesma discussão para a construção da identidade desse sujeito da contemporaneidade que, quase que obrigatoriamente, tem a necessidade de ordenar as diversas identidades que assume, administrando inclusive, suas representações visuais e gráficas.

Essas representações transitam pelo espaço físico e o meio digital e abrem para o 
sujeito a possibilidade de rever sua identidade e até mesmo remodelar a dualidade "belo" e "feio" através do avatar, no caso dos games. Aristóteles assimila o feio como uma parte do belo, ampliando assim o conceito de beleza. Seguindo a lógica aristotélica, vemos que sua análise da beleza está centrada no sujeito, na fruição dos objetos e na harmonia gerada pelo ordenamento das partes; portanto, esse ordenamento pode inclusive transformar o repulsivo, o não-humano, o indesejável, em algo aceitável, um componente harmônico dessa construção do objeto sujeito.

Nasce uma combinação de criaturas pós-humanas e outros híbridos, que como dissemos anteriormente, enevoa os limites que deixavam claro as delimitações de cada fragmento que compõem harmonicamente nossa identidade. Significa dizer que, para que o processo de construção de subjetividade ocorra, há a necessidade de que também possamos identificar o outro. É aí então que o processo de hibridação homem-máquina ou sujeito do mundo físico e sujeito que habita os metaversos dos jogos nos leva a uma crise: quem é o "eu" e quem é o "outro"? Essa questão torna a investigação sobre a relação estabelecida entre o sujeito contemporâneo e o game, perpassando pela noção de corpo dentro dos ambientes virtuais, ainda mais relevante.

Rudiguer (2008) aponta que o sentimento de conexão com nossos artefatos maquínicos está aumentando gradativamente, nos deixando cada vez mais confortáveis com essa ampliação de habilidades e de sentidos proporcionada pela hibridação com a tecnologia. Cada vez fica mais evidente que a corporeidade proporcionada pelo avatar dentro do contexto do game carrega em si também uma certa transposição de identidade. O "eu" do jogador passa uma fração sua a esse corpo virtual, construído dentro do ambiente do jogo, ajudando a construir o que podemos chamar de "identidade virtual".

\subsection{Subjetividade e Identidade virtual}

Matuk e Meucci (apud: Colen \& Queiroz, 2010) mencionam que a identidade virtual, discutida por autores como Turkle e Levy, se configura como um conjunto de características, a princípio, auto atribuídas. Tais características passam a ser reconhecidas por grupos (alo-definição) e tornam os ícones ou palavras que as sintetizam, interfaces por meio das quais a pessoa se expressa e interage em ambientes e comunidades virtuais. Percebe-se que o termo "avatar" é usado de maneira trivial para designar essa identidade virtual dos jogadores, tornando-se a interface que media a relação do jogador com o jogo e também o elemento que o personifica, permitindo que outros jogadores o reconheçam como indivíduo.

Significa dizer que o avatar amplia o sentido de corpo-coisa, ganhando status de "corpóreo". Dessa maneira o avatar se apresenta possuindo assim um sentido duplo, designando ao mesmo tempo a estrutura vivida e o contexto, ou lugar, de mecanismos cognitivos que nos permitem identificar traços indenitários do jogador na construção dessa figura, entendida por muitos como "artífice de experiências interativas diversas". Tratar de interação significa voltar a essência do jogo, o ganhar e o perder e às categorias do jogo elencadas por Calois.

Ao analisar a natureza dos jogos, Caillois (1990) estabeleceu que cada tipo de jogo seduz o homem por sua ludicidade e pelo prazer que proporciona. Caminhando nessa classificação, o autor estabeleceu categorias diferentes para os jogos existentes, sendo estas as quatro mais relevantes: os jogos de competição (Agon), os de azar (Alea), os de simulacro, de teatro (Mimicry) e os de vertigem, em que se procura uma sensação de entorpecimento (Ilinx). Categorias essas aplicadas na esfera física e digital quando falamos de jogos, espaço de construção de uma dialética.

O cerne da discussão residiria no exame das relações construídas nesse processo 
dialético entre o real e o digital ${ }^{9}$, voltando nossas atenções para o ambiente, seus jogadores e os avatares. Vemos que é nesse contexto, onde o sujeito contemporâneo encontra na cibercultura a possibilidade de dar corporeidade a desdobramentos subjetivos, que surgem questões que perpassam pelos campos da comunicação e da cultura visual, nos permitindo também criar conexões com diversos universos simbólicos.

A construção de novos universos simbólicos, dimensão ligada ao contexto sociológico e cultural, altera a noção que tínhamos a respeito de presença e de lugar, uma outra implicação da ocupação desses universos virtuais. A dimensão corpórea rompe a barreira do físico e passa a habitar o não-lugar, já que "a territorialidade parece ultrapassar os conceitos geográficos e do urbanismo ortodoxo para atingir as dimensões possíveis dos sistemas midiáticos", como aponta Takahashi (2010):

A presença virtual é de fato a conquista de não lugares, mas o corpo físico, que não acompanha fisicamente esta operação, perde-se no universo atemporal das simulações. Com as possibilidades cada vez mais abrangentes de conquista de não lugares, o corpo se definha em suas capacidades de percepção ambiental (TAKAHASHI, 2010, p. 136)

Trata-se de um deslocamento, onde lugar e presença trasladam do plano unicamente físico para um campo mais conceitual e simbólico, o da tele presença. Oliver Grau (2007) ao descrever tele presença exemplifica a ação de um usuário que opera um robô à distância. A simultaneidade de movimentos entre robô e usuário não é nada diferente da relação estabelecida entre jogador e avatar, em ambos "o usuário desloca-se em uma representação simulada por computador” (GRAU 2007)

Partindo de uma tradução imagética permitida pelo avatar, constrói-se nesse ambiente uma nova perspectiva do "eu no mundo", adaptada as demandas desse lugar. Esse novo eu (corporificado pelo avatar) não se isola do primeiro eu, o físico, ou de outros "eus" que esse sujeito possua. O que se observa é a dialética entre as instâncias on-line e off-line, relação composta por contiguidades e rupturas. Caminhando para a construção de algo que extrapola o registro imagético do avatar, caminhando para o que muitos identificam como "identidade virtual".

\section{CONSIDERAÇÕES FINAIS: IDENTIDADE CONTEMPORÂNEA, REPRESENTAÇÃO E FRAG- MENTAÇÃO.}

Como pudemos ver o processo de construção da identidade de cada um de nós agregou, contemporaneamente, às questões que já tornavam difícil a definição do "eu", alguns novos fatores intimamente ligados a crescente hibridação com as novas tecnologias. Sibila (2002) identifica no sujeito pertencente a essa época uma busca pela definição desta fronteira (entre "eu" e "outro", entre "humano" e "não-humano") uma busca que gera respostas ambíguas e não definitivas.

Enquanto Guattari identifica no processo de construção de subjetividades um poder de elaboração desse entendimento, outros autores percebem que não há como negligenciar a potencial hibridação humano-máquina a que o homem contemporâneo está exposto. Nota-se uma aproximação entre imagens mentais e visuais e uma importância crescente do processo de representação para que, de alguma maneira, consigamos visualizar como estes fragmentos subjetivos vão se organizando. Eclodem as mais variadas versões destes seres híbridos e não delineados, reforçando a ideia do papel determinante que a imagem exerce sobre a sociedade ocidental pós-moderna.

No universo dos jogos digitais nos parece que a para o jogador essa hibridação humano-

\footnotetext{
9 Tomando aqui o real no sentido mais raso, ligado aos fatos, podendo ampliar esse entendimento caminhando pra diferenciação entre "real" e "realidade". De acordo com HELD (1980), se diferenciarmos realidade e real teremos o real como uma construção que passa, necessariamente, pelo imaginário. Sob esse aspecto, a realidade e o digital podem ser e são reais.
} 
máquina passa despercebida, quase inconsciente. Ao se colocar no metaverso do jogo por meio de um avatar, cuja customização por vezes the garante altos graus de subjetividade e diferenciação, o jogador assimila esse hibridação como natural, agregando a ela valores e conceitos que pertencem, por vezes unicamente, aquele metaverso. Temos no avatar uma representação gráfica cuja carga simbólica irá variar tanto de sujeito para sujeito, quanto de metaverso para metaverso.

Portadoras de símbolos e valores agregados, as imagens visuais e as representações gráficas possuem uma pluralidade que, como aponta Bachelard (apud DURAND 1999), contém seu próprio tempo e espaço, numa relatividade específica e não assimétrica. É um sistema composto por significações e símbolos onde as explicações lineares ou por lógica dedutiva não são suficientes para estudar suas motivações. Para Durand (1999):

\begin{abstract}
Torna-se necessário procurar as categorias motivantes dos símbolos nos comportamentos elementares do psiquismo humano, reservando para mais tarde o ajustamento desse comportamento aos complementos diretos ou mesmo aos jogos semiológicos. (DURAND, 1999, p. 62)
\end{abstract}

Símbolos e sinais são empregados nos possibilitando uma análise dessa representação. Encontramos elementos que nos permitem especular que valores foram agregados àquela imagem, seja ela visual ou verbal. Mesmo que esta identidade esteja constantemente em mutação, identificamos uma necessidade de construí-la, pois ela é responsável por parte das significações que produzimos enquanto sujeitos. Sem essa identidade, originada pelo próprio sujeito através de um processo de individualização (Castells: 2003), a tarefa de cumprir ao diversos papéis que exercemos no dia-a-dia torna-se mais difícil.

Essa designação de características capazes de separar o eu e o outro se constrói em instâncias conectadas por construções que contam com elementos depositados no imaginário. São esses elementos que nos permitem validar as representações que atribuímos a nós mesmos e estabelecer também qual é nosso lugar no mundo.

É assim que, através dos seus imaginários sociais, uma coletividade designa a sua identidade; elabora uma certa representação de si; estabelece a distribuição de papéis e das posições sociais [...] O imaginário social torna-se inteligível e comunicável através da produção dos "discursos" nos quais e pelos quais se efectua" (BACZKO, 1985, p. 309-311)

Nessa conexão entre a subjetividade e os imaginários que validam as relações sociais dentro do jogo, percebemos que o avatar também se apresenta numa multiplicidade de vozes, sendo ora objeto, ora sujeito, ora elemento que compõe um imaginário que, por fim, termina por validá-lo enquanto representação do sujeito jogador nesse ambiente de jogo. Concluímos que o avatar é todo e é fragmento, bem aos moldes do que a harmonia Aristotélica propõe já que ele é ao mesmo tempo parte da identidade do jogador e parte de um sistema maior, aquele que valida a identidade adotado pelo jogador ali naquele metaverso.

\title{
REFERÊNCIAS
}

ARISTÓTElES; HORÁCIO \& LONGINO, A Arte Poética. São Paulo: Cultrix, 2010.

BACZKO, B., A imaginação social, In: LEACH, Edmund et Al.,. Anthropos-Homem. Lisboa: Imprensa Nacional/Casa da Moeda, 1985.

CAILLOIS, R. Os jogos e os homens. Lisboa: Portugal, 1990.

CASTELLS, M. A Sociedade em Rede. São Paulo: Paz e Terra, 2007.

0 poder da Identidade (volume 02). São Paulo: Paz e Terra, 2003. 
CASTRONOVA, E, Virtual Worlds: A First-Hand Account of Market and Society on the Cyberian Frontier. In: CESifo Working Paper, 2001, nº. 618, December. (on line), 2001 Disponível em: <<http://papers.5srn.com/sol3/papers.cfm?abstract_id=294828>> Acessado em 08.fev.2017.

COLEN, E.M. \& QUEIROZ e MELO, M de F. Os avatares como mediadores no jogo de papéis. In: Revista Lapid - vol. 05, nำ .2010. Disponível em: <<HTTP://www.ufsj.edu. br/porta2-repositorio/file/revistalapip/volume5_n1/colen_e_queiroz_e_melo.pdf >> Acessado em 08.fev.2017.

DINIZ, L.A.G. Ciborgues, Subjetividades Maquínicas, Cíbridos e Híbridos E o Imaginário Contemporâneo. In: Artefactum - Revista de Estudos em Linguagem e Tecnologia, ano V, no 1, maio. 2013. Disponível em: << http://artefactum.rafrom.com.br/index.php/ artefactum/article/view/127/213 >> Acessado em 15.jan.2017.

DURAND, G. O Imaginário. São Paulo: Difel, 1999.

FRANÇA, V. R. V., Discurso de identidade, discurso de alteridade: a fala do outro. In: FRANÇA, V. R. V. (org) Imagens do Brasil: modos de ver, modos de conviver. Belo Horizonte: Autêntica. 2002

GRAU, O. Arte Virtual. São Paulo: Editora UNESP, Editora SENAC, 2007.

GUATTARI, F, Caosmose: Um novo paradigma estético. São Paulo: Editora 34, 1992.

HALL, S. A, Identidade cultural na pós - modernidade. Rio de Janeiro: DP\&A editora, 2005.

HARAWAY, D. Simians, Cyborgs, and Women: The Reinvention of Nature. Nova York : Routledge. 1991

LEMOS, A. Cibercultura, cultura e identidade: em direção a uma "Cultura Copyleft"? In: Contemporânea - Revista de Comunicação e Cultura, vol.2, no 2, p 9-22, Dezembro. 2009. Disponível em: << http://www.portalseer.ufba.br/index.php/ contemporaneaposcom/article/view/3416/2486 >> Acessado em 10.mar.2017

LOPES, D. A. Entre Evas e Humanos: uma abordagem da relação homem - máquina através da animação japonesa néon genesis evangelion. Dissertação . (mestrado em Cultura Visual) Programa de Cultura Visual, FAV-UFG. 2006.

RUDIGUER, F. Cibercultura e pós-humanismo. Porto Alegre: EDIPUCRS, 2008.

SIBILA, P. O homem pós-orgânico: corpo, subjetividade e tecnologias digitais. Rio de Janeiro: Relume Dumará, 2002.

SILVA, T. T. (org), Pedagogia dos Monstros: 05 prazeres e 05 perigos da confusão de fronteiras. Belo Horizonte: Autêntica, 2001.

TAKAHASHI, J., Dimensões do corpo contemporâneo. In: GREINER, Christine \&\& AMORIN, Claudia (org.), Leituras do Corpo. São Paulo: Annablume, 2010. 